\title{
Ungeschriebener Parlamentsvorbehalt und akademische Selbstverwaltungsgarantie
}

Ein Beitrag zur Reichweite der Satzungsautonomie wissenschaftlicher Hochschulen im Bereich des Promotionswesens

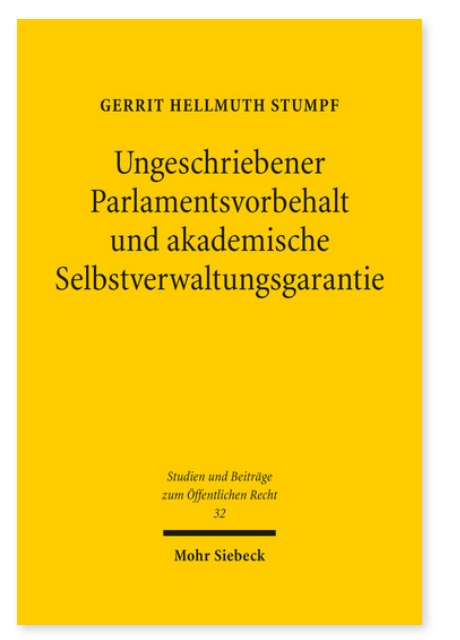

2017. XXXIV, 839 Seiten. StudÖR 32

ISBN 978-3-16-154582-5

DOI 10.1628/978-3-16-154582-5

eBook PDF $174,00 €$

ISBN 978-3-16-154581-8

Leinen $174,00 €$
Zwischen dem Anspruch der Hochschulen, den Zugang zur Promotion exklusiv regeln zu wollen, und der vom Bundesverfassungsgericht im Lichte der Lehre vom ungeschriebenen Parlamentsvorbehalt gezogenen Autonomiegrenze besteht eine Diskrepanz. Diese bildet für Gerrit Hellmuth Stumpf nicht nur den Ausgangspunkt für die Untersuchung, der vermeintlich längst geklärt geglaubten - Frage, wer, akademischer Satzungs- oder Parlamentsgesetzgeber, den Zugang zur Promotion regeln darf, sondern auch den Anlass, um in diesem Kontext der Existenzberechtigung institutioneller Garantien im Bereich der Wissenschaftsfreiheit, dem Verhältnis von Art. 5 Abs. 3 Satz 1 GG zu den landesverfassungsrechtlichen Selbstverwaltungsgarantien, dem damit zusammenhängenden Verhältnis von Landes- und Bundes(verfassungs-)recht und der (demokratischen) Legitimation der akademischen Satzungsgeber im Vergleich zu der des Parlamentsgesetzgebers nachzugehen.

Gerrit Hellmuth Stumpf Bankkaufmann; Studium in Köln, Bonn, Sydney (LL.M.) und Münster (Executive MBA); Rechtsreferendariat im Bezirk des Oberlandesgerichts Köln; Akademischer Rat a.Z. am Lehrstuhl für Öffentliches Recht an der Rheinischen Friedrich-Wilhelms-Universität zu Bonn.
Jetzt bestellen:
https://mohrsiebeck.com/buch/ungeschriebener-parlamentsvorbehalt-und-akademische-selbstverwaltungsgarantie-
9783161545825?no_cache=1
order@mohrsiebeck.com
Telefon: +49 (0)7071-923-17
Telefax: +49 (0)7071-51104 